\title{
The effectiveness of a psycho-educational group after early-stage breast cancer treatment: results of a randomized French study
}

\author{
S. Dolbeault ${ }^{1,2,3^{*}}$, S. Cayrou ${ }^{4}$, A. Brédart ${ }^{1,5}$, A. L. Viala ${ }^{1}$, B. Desclaux ${ }^{4}$, P. Saltel ${ }^{6}$, A. Gauvain-Piquard ${ }^{7}$, \\ P. Hardy ${ }^{3,8,9}$ and P. Dickes ${ }^{10}$ \\ ${ }^{1}$ Psycho-Oncology Unit, Curie Institute Paris, France \\ ${ }^{2}$ Univ Paris-Sud and Univ Paris Descartes, France \\ ${ }^{3}$ INSERM, U669, Paris, France \\ ${ }^{4}$ Psycho-Oncology Unit, Claudius Regaud Institute, Toulouse, France \\ ${ }^{5}$ Henri Piéron Psychology Institute, Université Paris Descartes, France \\ ${ }^{6}$ Psycho-Oncology Unit, Léon Bérard Center, Lyon, France \\ ${ }^{7}$ Psycho-Oncology Unit, Gustave Roussy Institute, Villejuif, France \\ ${ }^{8}$ Univ Paris-Sud, Le Kremlin Bicêtre, France \\ ${ }^{9}$ AP-HP, Le Kremlin-Bicêtre, Inserm, Paris, France \\ ${ }^{10}$ Univ Nancy II, Laboratory of Psychology—Grapco, Nancy, France
}

* Correspondence to: PsychoOncology Unit, Institut Curie, 26 rue d'Ulm, 75248 Paris cedex 05, France. E-mail: sylvie.dolbeault@curie.net

\begin{abstract}
Background: Many women with breast cancer need psychological help to cope more effectively after treatment. Cognitive and behavioural techniques are not yet well established in France. A multi-site randomized study was conducted to evaluate the effects of a psycho-educational group intervention in this population.

Methods: Two hundred and three patients, recruited after primary treatment, were randomly assigned either to a treatment group (psycho-educational intervention) or to a waiting-list control group. The 8 -week programme of $2 \mathrm{~h}$ sessions comprised of thematic discussions, information and training in stress management techniques. Evaluation at baseline, after 8 sessions, and 1 month after programme completion, included evaluations using the STAI, POMS, MAC, EORTC QLQ-C30 and EORTC QLQ-BR23 breast module scales.

Results: We observed a significant reduction in anxiety (STAI, POMS) among group participants, a reduction in anger, depression and fatigue (POMS), a significant improvement in vigor and interpersonal relationships (POMS), in emotional and role functioning, in health status and fatigue level (EORTC QLQ-C30). In contrast, coping strategies (MAC) were not significantly different between groups. No group-related negative effects were observed and the global satisfaction levels were very high.

Conclusion: This study demonstrates the feasibility and effectiveness of a psycho-educational intervention, which can accelerate the reduction of those negative affects which are present at the end of treatment. It represents an excellent complement or an alternative to individual psycho-oncologic therapeutic support, widely proposed in France, and should now be tested in groups with other types of cancer and at other disease phases.
\end{abstract}

Keywords: group therapy; psycho-education; randomized controlled trial; breast cancer; oncology

\section{Introduction}

Women facing a diagnosis of breast cancer frequently develop psychopathological disturbances during medical treatment [1] or during follow-up [2], particularly anxiety, depression or both.

After treatment, women are concerned by the threat of death, the risk of recurrence, their uncertainty for the future, physical and treatment related problems, fatigue, sexuality, body image, relationships and occupational difficulties [3-6]. In this remission phase also called re-entry transition [7], they are confronted with many individual challenges in reverting from 'cancer patient' back to 'person' and they have to cope with a new experience of the disease in a complex rehabilitation process $[8,9]$.

All these concerns can create psychosocial adjustment disturbances, including anxiety, depression, 
other affects or coping disabilities. Symptoms of anxiety can arise from follow-up medical examinations, as can post-traumatic symptom disorders when dealing with physical and mental changes, feelings of abandonment by professionals or isolation from the partner and family [7].

Because of the high prevalence of psychological or psychiatric problems in breast cancer patients, a wide range of psychosocial interventions have been developed, which are diverse in type, target population, format and outcome [10-13]. The meta-analysis by Sheard and Maguire [14] exploring anxiety and depression, reported a positive impact of psychotherapeutic interventions, with group interventions proving to be superior.

A number of studies have assessed the efficacy of cognitive behavioural techniques (CBT) or psychoeducational methods inspired from $\mathrm{CBT}$ in cancer patients, and a majority of these studies found significant positive outcomes for anxiety, depression, fatigue and general cancer distress $[15,16]$; among them, a recent meta-analysis [17] concerning breast cancer confirmed the efficacy of CBT both on distress and pain, and confirmed effect sizes found for distress in previously published meta-analyses $[14,15,18]$.

To our knowledge, most studies assessing the effectiveness of psychosocial interventions in earlystage breast cancer have been performed for diagnosis or initial treatment rather than during the remission phase $[3,12,19,20]$.

With some exceptions [21,22], most trials have been performed in English-speaking cultures, preventing extrapolation of results to the French context. Indeed, psycho-oncology in France has been developed mainly by the professionals trained in the use of psychodynamic techniques, involving individual patient follow-up using psychoanalytic methods, with a reluctance for consultation-liaison techniques. Very few psycho-oncologists are trained in CBT, brief therapy techniques and concepts of patient education. French patients are not familiar with group approaches, whether they concern psychology, psychiatry or oncology.

Given our cultural context, which is quite different from Anglo-American cultures and those of many other European countries, the challenge was to explore the feasibility of new psychooncology approaches in France [23], using both group formats and therapeutic tools from the psycho-educational field.

\section{Methods}

\section{Purpose}

This randomized trial aimed to assess the effectiveness of a psycho-educational group (PEG) intervention on anxiety, mood, mental adjustment and quality of life in early-stage breast cancer. As our first objective, we hypothesized a significant reduction in anxiety-a possible result of posttreatment patients' feelings - in the PEG compared with the control group (CG). Our secondary objectives included an improvement of patients' adjustment strategies and quality of life profiles as a result of the group intervention.

\section{Design and sample}

After receiving permission from the Institutional Review Board of Clinical Research and National Ethics Committee, this randomized pre-post intervention study was conducted in three French cancer centres. Eligible women (1) were 18 or older, (2) had completed primary breast cancer treatment (radiation alone or combined chemoradiotherapy 15 days to 1 year before testing), (3) had no recurrence or metastases, (4) had working knowledge of French, (5) had no psychiatric diagnosis such as severe cognitive disorders, mood disorders (ongoing or recent history of depression requiring hospitalization) or serious personality disorders.

Approximately 1000 letters were sent out, and an estimated $20 \%$ of those patients contacted answered positively. Randomization was performed to distribute the eligible patients after an interview to clarify their motivations. The final sample consisted of 203 early-stage breast cancer patients (Paris, 107; Toulouse, 51; Lyon, 45) randomized between the 'immediate' treated group (TG: n 5 102) and the 'deferred' control group (CG: n 5 101). Randomization by sealed letter was performed at each site, with a readjustment of the number of subjects in each group after every eighth subject. After randomization, patients who dropped out were not replaced. Patients who missed four group sessions were excluded from the analyses.

Assessments were performed three times on all participants: 1 week before starting the immediate intervention (E1), the second after completion of the intervention (E2) and the third, one week before the beginning of the deferred intervention (E3). Assessment at E1 was performed in the hospital and E2 and E3 were done at home (Figure 1).

\section{Intervention}

On the basis of previous studies with group interventions for women with breast cancer [2428], a psychoeducationally structured model based on CBT principles was developed. Patients were taught to routinely use thought records, to practise problem-solving and cognitive restructur- ing, to communicate better with caregivers and health professionals through role-play, and to practice relaxation. Unlike a comprehensive CBT 


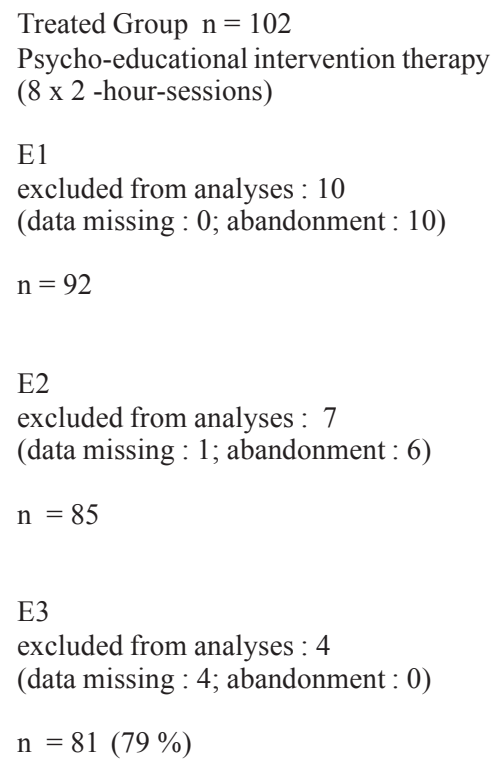

Control Group n $=101$

(Waiting Group)

excluded from analyses : 5

(data missing : 1 ; abandonment : 4)

$\mathrm{n}=96$

excluded from analyses : 3

(data missing : 0 ; abandonment : 3 )

$\mathrm{n}=93$

excluded from analyses : 6

(data missing : 0 ; abandonment : 6 )

$\mathrm{n}=87(86 \%)$

Figure 1. Trial profile outlining RCT design with numbers of patients at each stage

Table 1. Socio-demographic and clinical variables by randomization arm (significant data only)

\begin{tabular}{|c|c|c|c|c|}
\hline Variables & & Group (n 5 102) & Control (n 5 101) & $P$ \\
\hline Age & Mean (SD) & $54.5(9.3)$ & $51.6(9.6)$ & 0.03 \\
\hline Marital status & & & & 0.34 \\
\hline Education & & & & 0.47 \\
\hline Occupation & & & & 0.41 \\
\hline Return to work & & & & 0.24 \\
\hline Psychological assistance before diagnosis of cancer & & & & 0.41 \\
\hline \multirow[t]{4}{*}{ Psychological assistance since diagnosis of cancer } & None & 45 & 27 & 0.02 \\
\hline & Psychotherapy & 9 & 11 & \\
\hline & Psychotropic & 23 & 28 & \\
\hline & Psychotherapy and psychotropic & 16 & 23 & \\
\hline Psychological assistance at randomization & & & & 0.64 \\
\hline Previous therapy group experience & & & & 0.25 \\
\hline Time between diagnosis and randomization (months) & & & & 0.62 \\
\hline Time between end of treatment and randomization (months) & & & & 0.86 \\
\hline Stage & & & & 0.89 \\
\hline Radiotherapy & & & & 0.68 \\
\hline \multirow[t]{2}{*}{ Chemotherapy } & No & 56 & 39 & 0.02 \\
\hline & Yes & 46 & 62 & \\
\hline Endocrine therapy & & & & 0.32 \\
\hline
\end{tabular}

approach, all PEG exercises were initiations combined with general medical information and peer exchanges on defined themes (causes and significance of cancer, impact of treatments on body image, managing uncertainty, improving communication with loved ones, etc.). The programme included 8 weekly $2 \mathrm{~h}$ sessions. The groups were composed of 8-12 participants led by 2 therapists, either psychologists or psychiatrists, trained in group therapy and BCT [23].

The intervention was free of charge for patients, therapists being paid by hospital and research funding. The detailed content of this PEG has been described elsewhere [29] and a manual (2001) can be obtained by written request from the first author. Monthly meetings were organised with leaders, co-leaders and investigators to ensure the coherence of intervention delivery.

\section{Measurements}

Socio-demographic and medical data, disease stage, time since diagnosis and treatments received - either medical (surgery, chemotherapy, radiotherapy) or psychological (individual support, psychotropic drugs) - were recorded (Table 1). 
Table 2. Variables influenced by age and chemotherapy

\begin{tabular}{|c|c|c|c|}
\hline & $\begin{array}{c}\text { Confounding } \\
\text { Variables }\end{array}$ & $\begin{array}{c}\text { Inter-subject } \\
\text { effects }^{\mathrm{a}} \\
\mathrm{P}<0.05\end{array}$ & $\begin{array}{c}\text { Intra-subject } \\
\text { effects } \\
\mathrm{P}<0.05\end{array}$ \\
\hline Anx & Age & & 0.006 \\
\hline Ang & Age & & 0.006 \\
\hline Fat & Age & 0.012 & 0.048 \\
\hline $\mathrm{ScG}$ & Age & & 0.005 \\
\hline $\mathrm{RF}$ & Age & 0.039 & \\
\hline $\mathrm{EF}$ & Age & 0.033 & \\
\hline FA: fatigue & Age & 0.004 & \\
\hline NV: nausea & Age* ${ }^{*}$ cte & 0.034 & \\
\hline \multirow[t]{2}{*}{ PA: pain } & Age & 0.031 & \\
\hline & Cte & 0.010 & \\
\hline AP: appetite & Cte & 0.016 & \\
\hline \multirow[t]{2}{*}{ CO: constipation } & Cte & & 0.012 \\
\hline & Cte* age & & 0.036 \\
\hline FI: financial difficulties & Age* cte & & 0.050 \\
\hline BRBI: body image & Age & & 0.020 \\
\hline $\begin{array}{l}\text { BRSEF: sexual fonc- } \\
\text { tion }\end{array}$ & Age & 0.012 & 0.005 \\
\hline BRST: side effects & Age & & 0.039 \\
\hline \multirow{2}{*}{$\begin{array}{l}\text { BRBS: breast symp- } \\
\text { toms }\end{array}$} & Cte & 0.001 & 0.003 \\
\hline & Age & & 0.026 \\
\hline
\end{tabular}

${ }^{a}$ Inter-subject effect: group effect.

${ }^{\mathrm{b}}$ Intra-subject effect: time effect.

Patients completed validated French versions of the following self-report questionnaires.

Anxiety was measured using the State-Trait Anxiety Inventory (STAI, whose scores range from 20 to 80 with a higher score reflecting a higher level of anxiety [30,31]). Psychological adjustment was assessed with the Profile of Mood States (POMS) [32-34], comprising different scales: anxiety (with scores ranging from 0 to 36 ), anger (0 to 48), confusion (0 to 28 ), depression (0 to 60), fatigue (0 to 28$)$, vigor (0 to 32 ), interpersonal relationships (0 to 28). It includes a global score (from -32 to 200). A higher score indicates an increasing intensity of the mood state, whether it be negative affects (e.g.: anxiety, anger) or positive affects (e.g.: vigor, relationships). The Mental Adjustment to Cancer Scale (MAC) [35-37] provides 5 subscales measuring fighting spirit (13-52), helplessnesshopelessness (11-44), anxious preoccupation (1248), avoidance (5-20) and denial (3-12). High- er scores indicate a higher level of the mental adjustment score.

Patients' quality of life profiles were evaluated by the EORTC core quality of life questionnaire (EORTC QLQ-C30) [38,39] and breast cancer module (EORTC QLQ-BR23). Items are scored from 1 to 4, except the global health status items, which range from 1 to 7 . A high score for functional or global health status scales represents a healthy level of functioning; a high score for a symptom scale/item indicates a high level of symptoms or problems [40].
The EORTC core was administered only at E1 and $\mathrm{E} 3$ to reduce evaluation fatigue.

\section{Statistical analyses}

For missing data, we applied the method of data allocation recommended by Jöreskog \& Sörbom [41] using PRELIS software.

Statistical analyses were performed using SPSS and LISREL software. Statistical significance was set at $\mathrm{p}=0.05$.

The main objective of the statistical analyses was to compare the course of the two groups between E1 and E3, including E2, on STAI state and trait anxiety scales, after confirming their comparability at E1 on all socio-demographic and medical variables as well as psychosocial evaluations.

Quantitative socio-demographic data were analysed using parametric tests (Student t-test) and qualitative variables or variables without a normal distribution were analysed using non-parametric tests (Pearson's chi-square test or the Mann-Whitney U-test). We used general linear models to test dependent variables. These models present the advantage of providing t-test values for each variable, and a general value (Wilks' lambda) that takes all the variables entered into the model and their correlations into account.

We compared the course of the two groups between E1 and E3 using the general linear models with repeated measurements, which take all three measures into account, to distinguish between intra-subject effects (time effect and time-by-group interaction) and inter-subject effects. Statistical analyses also controlled for confounding variables, partly responsible for the variance of the scores of the variables measured.

The effects of confounding variables were tested in a preliminary analysis. First, they were entered as fixed criteria, without the group variable, in a repeated measures model for each dependent variable. If a significant effect was observed, then the variables were considered as covariates and remained in the complete model when the group differences were tested. If no significant effects were observed, only the groups were considered as independent variables, without covariates.

\section{Results}

\section{Sample characteristics}

Of the 203 women recruited for the study, 33 (16.3\%) dropped out: 14 from the TG and 19 from the CG. The main reasons were: disappointment with the group $(n=7)$, disappointment with the randomized allocation $(\mathrm{n}=6)$, work problems $(n=4)$, transportation problems $(n=3)$, family problems $(n=3)$, other non-cancer health problems 
Table 3. Comparison of change scores between randomization arms (Group: $n=81$; Control: $n=87$ )

\begin{tabular}{|c|c|c|c|c|c|c|c|}
\hline & & E1 Mean (SD) & E2 Mean (SD) & E3 Mean (SD) & & $\mathrm{p}$ & $\mathrm{Eta}^{2}$ \\
\hline \multirow[t]{3}{*}{ STAI Y-A } & Group & $46.27(13.87)$ & $40.60(11.43)$ & $39.75(10.55)$ & Intra-subject & 0.001 & 0.06 \\
\hline & Control & $43.85(12.16)$ & $45.77(12.68)$ & 43.85 (10.94) & Inter-subject & 0.140 & 0.01 \\
\hline & & & & & Time $\mathbf{x}$ group & 0.001 & 0.06 \\
\hline \multirow[t]{3}{*}{ STAI Y-B } & Group & $47.53(10.42)$ & $43.22(10.02)$ & $42.25(10.04)$ & Intra-subject & 0.000 & 0.17 \\
\hline & Control & $47.48(9.31)$ & $47.94(10.46)$ & $45.46(10.17)$ & Inter-subject & 0.064 & 0.02 \\
\hline & & & & & Time $\mathrm{x}$ group & 0.010 & 0.04 \\
\hline \multirow[t]{3}{*}{ POMS Anxiety $^{\mathrm{a}}$} & Group & $15.12(8.11)$ & $10.58(6.89)$ & $9.90(6.44)$ & Intra-subject & 0.001 & 0.07 \\
\hline & Control & $14.69(7.63)$ & $14.71(8.35)$ & $12.78(7.45)$ & Inter-subject & 0.059 & 0.02 \\
\hline & & & & & Time $\mathbf{x}$ group & 0.000 & 0.08 \\
\hline \multirow[t]{3}{*}{ POMS Anger ${ }^{a}$} & Group & $13.83(8.71)$ & $9.74(7.43)$ & $9.49(6.81)$ & Intra-subject & 0.000 & 0.07 \\
\hline & Control & $13.29(8.64)$ & $14.28(9.11)$ & $11.44(7.91)$ & Inter-subject & 0.124 & 0.01 \\
\hline & & & & & Time $\mathrm{x}$ group & 0.005 & 0.05 \\
\hline \multirow[t]{3}{*}{ POMS Confusion } & Group & $8.78(4.85)$ & $7.12(4.73)$ & $6.91(4.74)$ & Intra-subject & 0.000 & 0.11 \\
\hline & Control & $9.84(5.70)$ & $10.11(6.24)$ & $8.90(5.83)$ & Inter-subject & 0.008 & 0.04 \\
\hline & & & & & Time $\mathbf{x}$ group & 0.149 & 0.01 \\
\hline \multirow[t]{3}{*}{ POMS Depression } & Group & $12.38(11.45)$ & $8.90(10.21)$ & $7.86(8.61)$ & Intra-subject & 0.000 & 0.14 \\
\hline & Control & $13.46(11.95)$ & $13.54(12.56)$ & $11.40(10.78)$ & Inter-subject & 0.047 & 0.02 \\
\hline & & & & & Time $\mathbf{x}$ group & 0.034 & 0.02 \\
\hline \multirow[t]{3}{*}{ POMS Fatigue $^{\mathrm{a}}$} & Group & $10.01(7.38)$ & $7.74(6.89)$ & $6.86(5.58)$ & Intra-subject & 0.069 & 0.02 \\
\hline & Control & $8.78(6.85)$ & $10.23(7.08)$ & $8.87(6.84)$ & Inter-subject & 0.370 & 0.01 \\
\hline & & & & & Time $\mathbf{x}$ group & 0.000 & 0.07 \\
\hline \multirow[t]{3}{*}{ POMS Vigor } & Group & $15.02(5.29)$ & $16.22(6.28)$ & $16.31(5.96)$ & Intra-subject & 0.109 & 0.02 \\
\hline & Control & $15.21(6.28)$ & $14.51(6.48)$ & $15.00(5.52)$ & Inter-subject & 0.253 & 0.01 \\
\hline & & & & & Time $\mathbf{x}$ group & 0.027 & 0.03 \\
\hline POMS Interpersonal & Group & $17.64(4.17)$ & $18.91(3.42)$ & $18.80(3.49)$ & Intra-subject & 0.166 & 0.01 \\
\hline \multirow[t]{2}{*}{ Relationships } & Control & $17.79(3.74)$ & $17.52(3.85)$ & $17.41(3.67)$ & Inter-subject & 0.072 & 0.02 \\
\hline & Group & & & & Time $\mathbf{x}$ group & 0.007 & 0.04 \\
\hline \multirow{4}{*}{$\begin{array}{l}\text { POMS } \\
\text { Global score }^{a}\end{array}$} & Group & $45.10(36.70)$ & $27.86(35.24)$ & $24.73(30.91)$ & Intra-subject & 0.001 & 0.06 \\
\hline & & & & & & & \\
\hline & Control & $44.85(37.83)$ & 48.37 (41.77) & $38.39(35.57)$ & Inter-subject & 0.040 & 0.03 \\
\hline & & & & & Time $\mathbf{x}$ group & 0.000 & 0.08 \\
\hline \multirow{3}{*}{$\begin{array}{l}\text { MAC Hopelessness/ } \\
\text { Helplessness }\end{array}$} & Group & $19.67(5.96)$ & $18.65(5.25)$ & $17.80(5.10)$ & Intra-subject & 0.000 & 0.12 \\
\hline & Control & $19.26(6.12)$ & $19.23(5.97)$ & $18.46(5.90)$ & Inter-subject & 0.737 & 0.00 \\
\hline & & & & & Time $\mathbf{x}$ group & 0.063 & 0.02 \\
\hline MAC & Group & $27.58(8.00)$ & $24.99(6.54)$ & $24.22(6.67)$ & Intra-subject & 0.000 & 0.29 \\
\hline \multicolumn{8}{|l|}{ Anxious } \\
\hline \multirow[t]{2}{*}{ Preoccupation } & Control & $27.70(6.70)$ & $26.57(6.84)$ & $25.29(6.62)$ & Inter-subject & 0.352 & 0.01 \\
\hline & & & & & Time $\mathrm{x}$ group & 0.183 & 0.01 \\
\hline EORTC & Group & $1.63(0.53)$ & - & $1.56(0.46)$ & Intra-subject & 0.027 & 0.03 \\
\hline \multicolumn{8}{|l|}{ Physical } \\
\hline \multirow[t]{2}{*}{ Functioning } & Control & $1.57(0.54)$ & - & $1.51(0.48)$ & Inter-subject & 0.43 & 0.00 \\
\hline & & & & & Time $\mathbf{x}$ group & 0.74 & 0.00 \\
\hline EORTC & Group & $1.84(0.83)$ & - & $1.55(0.66)$ & Intra-subject & 0.141 & 0.01 \\
\hline \multicolumn{8}{|l|}{ Role } \\
\hline \multirow[t]{2}{*}{ Functioning ${ }^{\mathrm{a}}$} & Control & $1.63(0.74)$ & - & $1.59(0.70)$ & Inter-subject & 0.372 & 0.01 \\
\hline & & & & & Time $\mathbf{x}$ group & 0.017 & 0.03 \\
\hline
\end{tabular}


Table 3. (Continued)

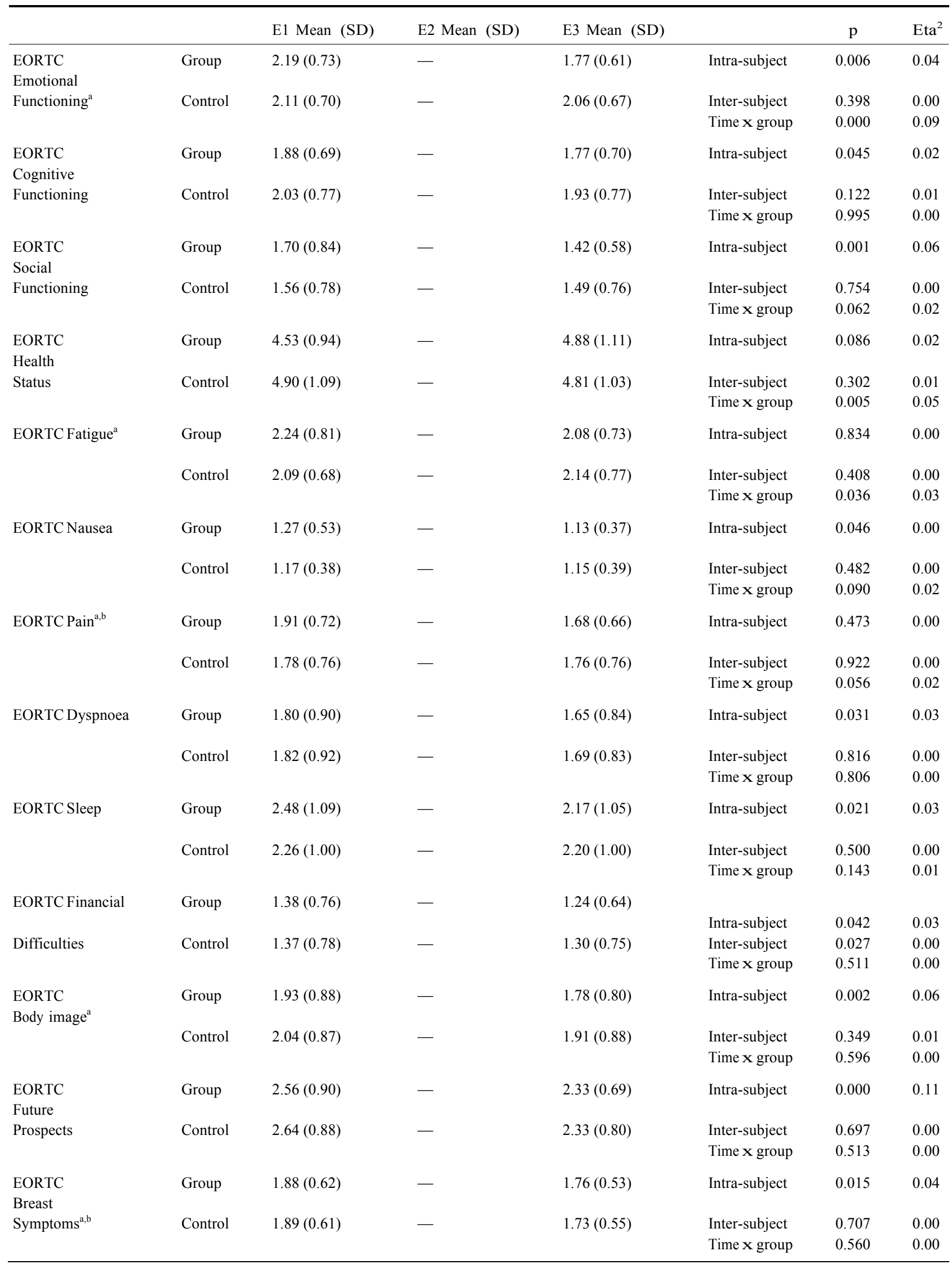

${ }^{a}$ Inter-subject effect: group effect.

${ }^{\mathrm{b}}$ Intra-subject effect: time effect.

Time $\mathrm{x}$ group: time/group interaction effect. Test controlled with 'age' as covariates; ${ }^{(\mathrm{b})}$ Test controlled with 'presence of chemotherapy' as covariates. The EORTC QLQC30 and BR23 were administered at E1 and E3 only. EORTC QLQ-BR23 hair loss and sexual satisfaction items were not included in the analyses because of missing responses (in both cases) or irrelevance (no more alopecia). Non-standardized rough scores are used to maintain a uniform significance of the mean values. 
$(\mathrm{n}=4)$, cancer recurrence $(\mathrm{n}=1)$, other reasons $(\mathrm{n}==)$.

Most patients attended all sessions. Absences were rare and were always motivated by material or health problems and were equivalent in both the TG and CG.

Patients who dropped out were not significantly different from PEG-participating patients as concerns their STAI, POMS and MAC scores at E1, but their socio-demographic characteristics were different. They were more frequently from the working class or were unemployed, compared with full-length participants who were more frequently from middle and high-level executive categories. They had also needed more extensive surgery (mastectomy with lymph node dissection versus tumorectomy) than did the other participants.

The overall missing data rate in questionnaires ranged from 0.02 to $6.29 \%$ (the sum of missing data divided by the product of the number of subjects and questionnaire items) depending on the questionnaire and assessment time. For up to $10 \%$ of the missing data, the described procedures were used to impute values, questionnaires being excluded afterwards.

\section{Comparisons of baseline characteristics between} groups

The two groups were comparable for all variables except age $(p=0.03)$ and the presence of chemotherapy $(\mathrm{p}=0.02)$. The $\mathrm{CG}$ was younger (mean age: 51.60 versus 54.47) and had more frequently received chemotherapy (57 versus 43\%). No significant difference was found for scores on the STAI, POMS, MAC, EORTC QLQ-C30 and QLQ-BR23 scales, except the EORTC QLQ-C30 'global health state' scale $(\mathrm{p}=0.01)$, where the $\mathrm{CG}$ reported better health status (data not shown).

Age (50 or under versus over 50) influenced the time-course of the POMS anxiety, anger, fatigue and global scores, the EORTC QLQ-C30 or QLQBR23 emotional and role functioning, fatigue, body image, sexuality, adverse effects and symptom scales. The presence of chemotherapy influenced the course of the EORTC QLQ-C30 pain, appetite, constipation and QLQ-BR23 breast symptom scores.

Comparisons of change in scores within and between treatment groups

Some patients were removed from the statistical multivariate analysis because they did not complete the three evaluations, a fact which explains the reduction in number from 102 to 81 in the TG and from 101 to 87 in the $\mathrm{CG}$.

As described in Table 3, in both groups changes were observed over time in the STAI trait and state anxiety scores, the POMS anxiety, anger, confusion, depression and global scores, the MAC helplessnes- shopelessness and anxious preoccupations scores, in the EORTC QLQ-C30 scores for physical, emotional, cognitive and social functioning, dyspnoea, sleep and financial difficulties, and in the QLQ-BR23 body image, future prospects and breast symptom scores.

Controlling for a time effect, significant group/ time interactions indicate a positive effect of the intervention on anxiety, our primary outcome measure. This was evidenced for the STAI state and trait anxiety scales, explaining $6 \%$ and $4 \%$ of the variance in the STAI-state and STAI-trait anxiety scores, respectively (Table 3 ).

We also found positive results on other variables identified as secondary outcome measures. A greater reduction of negative affects and improvement in positive affects and in quality of life functional or symptom scales were observed in the TG compared with the CG. This concerned the POMS anxiety and global scores $(8 \%$ of the variance explained by the model including the time/group interaction term), scores for fatigue $(7 \%)$, anger $(5 \%)$, interpersonal relationships $(4 \%)$, vigor $(3 \%)$ and depression $(2 \%)$ and the EORTC QLQ-C30 scores, emotional functioning $(9 \%)$, role functioning $(3 \%)$, global health status $(3 \%)$ and fatigue $(3 \%)$.

In contrast, no effect of the PEG was evidenced on the MAC scale or on the POMS confusion scores.

The study aimed to test the effect of PEG interventions on psychosocial adjustment in posttreatment early-stage breast cancer patients, in a multi-site French study. Controlling for age and past chemotherapy, a PEG intervention effect was clearly visible, as measured 1-month post-intervention, regardless of the passage of time, on patients' levels of anxiety and on mood states (except confusion), emotional and role functioning, fatigue and overall health status. However, no effect of the PEG was observed on mental adjustment, i.e. measures of emotional, cognitive or behavioural responses to the breast cancer experience in these patients in remission. Lower levels of helplessness-hopelessness or anxious preoccu pation were evidenced in TG and $\mathrm{CG}$ alike, reflecting spontaneous psychological improvement over time.

Our positive results are in line with data from other studies in different cultural contexts on the efficacy of group psychological therapy on mood disturbance, anxiety or depression in early-stage breast cancer patients [5,21,28], as well as on quality of life aspects, probably as a result of positive variations in emotional states $[6,42]$.

As noted in this study, Kissane et al. [5] did not find any effect of their intervention on mental adjustment scores. Conversely, using a similar intervention, Fukui et al. [21] found higher scores for fighting spirit among treated patients, 
immediately or 6 months after an educational intervention, and Helgeson et al. [43] highlighted better adjustment in post-diagnosis breast cancer patients participating in educational intervention compared with peer discussion groups.

Several hypotheses could explain our results; that is, the PEG effect observed on emotional states but not on mental adjustment.

The MAC scale has demonstrated its clinical sensitivity [44]. The lack of PEG effect on mental adjustment may be related to the psychotherapy technique used. Although our PEG was intended to teach targeted coping skills through techniques inspired from BCT, it was mixed with supportiveexpressive moments in each session, which may have emphasized the experiential facet of the therapy to the detriment of the educational part. The PEG respected the reluctance of some of the groups to directly confront subjects considered to be taboo-some authors $[25,26]$ think that this could be more effective in the long term. Indeed, groups may alleviate general anxiety by enabling patients to feel less isolated, legitimise personal feelings and find reassurance through peer exchanges, while maintaining a general avoidance attitude.

BCT-inspired techniques might need more than eight sessions to demonstrate improvement in adjustment strategies. Increases in anxiety for some patients while facing their experience during therapy could be a sign of mental adjustment, which could be beneficial in the long run. Further research is needed to pinpoint the specific mechanisms by which this type of intervention produces relief from anxiety or negative mood [45].

Our study presents certain methodological limitations.

The early implementation of the 'deferred' group therapy (for ethical reasons) prevented comparative assessment of long-term effects of the intervention.

Our results are based solely on subjective measures of psychological status, so there is a possible psychosocial bias (e.g. Hawthorne effect [46]). Objective measures such as return to work might be an important psychosocial outcome in breast cancer survivors [47].

There is no comparison of participants to nonparticipants.

The lack of complete data for one-fifth of the patients, who did not complete the questionnaires at all three evaluation times, weakens our results.

The sample was too small to evaluate differences between participating therapists (despite many efforts to ensure the consistency of intervention delivery), or to assess the specific impact of the PEG on sub-groups of patients defined by psychological characteristics.

However, despite these weaknesses, the PEGs clearly had an effect on our patients' anxiety and some aspects of mood and QOL.
Adding tools from group dynamics analysis could be useful in our PEGs so as to better understand the therapeutic process, including mechanisms of change.

Choosing anxiety as a primary outcome measure can be debated. Owen et al. [48] suggested variables reflecting patients' well-being as the most appropriate outcome measures to assess the effectiveness of psychological therapy in cancer patients.

Our PEG intervention recruited patients without criteria of significant clinical distress but, as recently suggested by various authors [49-51], short-term interventions could offer notable benefit to clinically distressed patients.

The interest of such interventions should now be tested in specific populations, bringing other sociodemographic variables into account like income or cultural origin (given the diversity of the French population), to determine which patients could benefit most $[52,53]$.

\section{Conclusion}

This experience proves that structured PEGs for French patients with early-stage breast cancer in remission have a positive effect on emotional states, especially in reducing anxiety levels. Although improvement in these outcomes was observed over time in both TG and CG , the PEG appeared to act as an accelerator of these effects. Further work should seek to identify and integrate breast cancer patients who particularly need this psychological approach, and to develop and test these psychotherapeutic techniques in the French cancer treatment milieu. PEGs represent an excellent complement or an alternative to the individual psycho-oncological treatment techniques, which are widely offered in France, and should now be tested in other types of cancer patients and in other stages of the disease.

\section{Acknowledgements}

This research received a grant from a French PHRC (Programme Hospitalier de Recherche Clinique (Hospital Programme of Clinical Research).

\section{References}

1. Kissane DW, Grabsch B, Love A, Clarke DM, Bloch S, Smith GC. Psychiatric disorder in women with early stage and advanced breast cancer: a comparative analysis. Aust N Z J Psychol 2004;38(5):320-326.

2. Burgess C, Cornelius V, Love S, Graham J, Richards M, Ramirez A. Depression and anxiety in women with early breast cancer: five year observational cohort study. BMJ 2005;330(7493):702.

3. Stanton AL, Ganz PA, Rowland JH, Meyerowitz BE, Krupnick JL, Sears SR. Promoting adjustment after 
treatment for cancer. Cancer 2005b;104(11 Suppl): 2608-2613.

4. Kornblith AB, Ligibel J. Psychosocial and sexual functioning of survivors of breast cancer. Semin Oncol 2003;30:799-813.

5. Kissane DW, Bloch S, Smith GC et al. Cognitiveexistential group psychotherapy for women with primary breast cancer: a randomized controlled trial. PsychoOncology 2003;12(6):532-546.

6. Shimozuma K, Ganz PA, Petersen L, Hirji K. Quality of life in the first year after breast cancer surgery: rehabilitation needs and patterns of recovery. Breast Cancer Res Treat 1999;56(1):45-57.

7. Stanton AL, Ganz PA, Kwan L et al. Outcomes from the Moving Beyond Cancer psychoeducational, randomized, controlled trial with breast cancer patients. J Clin Oncol 2005;23(25):6009-6018.

8. Carver CS. Enhancing adaptation during treatment and the role of individual differences. Cancer 2005;104(11 Suppl):2602-2607.

9. Ronson A, Body JJ. Psychosocial rehabilitation of cancer patients after curative therapy. Support Care Cancer 2002;10(4):281-291.

10. Newell SA, Sanson-Fischer RW, Savolainen NJ. Systematic review of psychological therapies for cancer patients: overview and recommendations for future research. J Natl Cancer Inst 2002;94:558-584.

11. Fawzy FI. Psychosocial intervention for patients with cancer: what works and what doesn't. Eur J Cancer 1999;35(11):1559-1564.

12. Vos PJ, Visser AP, Garssen B, Duivenvoorden HJ, de Haes HC. Effects of delayed psychosocial interventions versus early psychosocial interventions for women with early stage breast cancer. Patient Educ Couns 2006; 60(2):212-219.

13. Meyer TJ, Mark MM. Effects of psychosocial interventions with adult cancer patients: a meta-analysis of randomized experiments. Health Psychol 1995;14(2): 101-108.

14. Sheard T, Maguire P. The effect of psychological interventions on anxiety and depression in cancer patients: results of two meta-analyses. $\mathrm{Br} \mathrm{J}$ Cancer 1999;80(11):1770-1780.

15. Osborn RL, Demoncada AC, Feuerstein M. Psychosocial interventions for depression, anxiety, and quality of life in cancer survivors: meta-analyses. Int $\mathbf{J}$ Psychiatry Med 2006;36(1):13-34.

16. Savard J, Simard S, Giguè re I et al. Randomized clinical trial on cognitive therapy for depression in women with metastatic breast cancer: psychological and immunological effects. Palliat Support Care 2006;4(3): 219-237.

17. Tatrow K, Montgomery GH. Cognitive behavioral therapy techniques for distress and pain in breast cancer patients: a meta-analysis. J Behav Med. 2006;29(1): $17-27$.

18. Rehse B, Pukrop R. Effects of psychosocial interventions on quality of life in adult cancer patients: meta analysis of 37 published controlled outcome studies. Patient Educ Couns. 2003;50(2):179-186.

19. Bloom JR, Kessler L. Risk and timing of counseling and support interventions for younger women with breast cancer. J Natl Cancer Inst Monogr 1994;(16): 199-206.

20. Scheier MF, Helgeson VS, Schulz R et al. Interventions to enhance physical and psychological functioning among younger women who are ending nonhormonal adjuvant treatment for early-stage breast cancer. J Clin Oncol 2005;23(19):4298-4311.

21. Fukui S, Kugaya A, Okamura $\mathrm{H}$ et al. A psychosocial group intervention for Japanese women with primary breast carcinoma: a randomized controlled trial. Cancer 2000;89:1026-1036.

22. Okamura H, Fukui S, Nagasaka Y, Koike M, Uchitomi Y. Psychoeducational intervention for patients with primary breast cancer and patient satisfaction with information: an exploratory analysis. Breast Cancer Res Treat 2003;80(3):331-338.

23. Dolbeault S, Cayrou S, Viala AL. Psychoeducational group: a model of education for cancer patients. Rev Francoph Psycho-Oncol 2003;4(2):155-160.

24. Cain EN, Kohorn EI, Quinlan DM, Latimer K, Schwartz PE. Psychosocial benefits of a cancer support group. Cancer 1986;57:183-189.

25. Classen C, Diamond S, Soleman A, Fobair P, Spira J, Spiegel D. Brief Supportive-expressive Group Therapy for Women with Primary Breast Cancer: a Treatment Manual. Stanford University School of Medicine, Stanford, CA, 1993.

26. Fawzy IF, Fawzy NW. Patient Manual: Intervention for Cancer Patients. UCLA School of Medicine Psychiatry and Behavioural Sciences, USA-L.A. CA, 1993.

27. Kissane DW, Bloch S, Miach P, Smith CG, Seddon A, Keks N. Cognitive-existential group therapy for patients with primary breast cancer-techniques and themes. Psycho-Oncology 1997;6:25-33.

28. Spiegel D, Morrow GR, Classen C et al. Group psychotherapy for recently diagnosed breast cancer patients: a multicenter feasibility study. Psycho-Oncology 1999;8(6):482-493.

29. Cayrou S, Viala AL, Desclaux B, Saltel P, Dickes P, Dolbeault S. Groupes psycho-é ducationnels pour femmes atteintes de cancer du sein en France: the mes et techniques. JTCC 2005;15(1):15-21.

30. Spielberger CD. Manual for the State-Trait Anxiety Inventory (Forme Y). Consulting Psychologists Press: Palo Alto, CA, 1983

31. Schweitzer ML, Paulhan I. Manuel pour l'Inventaire d'Anxiéte Trait-Etat (Forme Y). Edition du centre de Psychologie Appliqué e, 1990.

32. McNair DM, Lorr M, Droppleman LP. EdITS Manual for the Profile of Mood States. Educational and Industrial Testing Service: EdITS San Diego, CA, 1992.

33. Cayrou S, Dickè s P, Gauvain-Piquard A, Dolbeault S, Callahan S, Rogé B. Validation de la traduction frane aise du POMS (Profile Of Mood States). Psychol Psychom 2000; 21(4):5-22.

34. Cayrou S, Dickè s P, Dolbeault S. Version frane aise du profile of mood states. JTCC 2003;13(2):83-88.

35. Watson M, Greer S, Bliss J. Mental Adjustment to Cancer Scale: User's Manual. The Royal Marsden Hospital, Sutton, Surrey, 1989.

36. Cayrou S, Dickè s P, Gauvain-Piquard A et al. Validation d'une version frane aise de la MAC (Mental Adjustment to Cancer) scale. Psychol Psychom 2001; 22(4):29-57.

37. Cayrou S, Dickè s P, Gauvain-Piquard A, Rogé B. The Mental Adjustment to Cancer (MAC): French replication and assessment of positive and negative adjustment dimensions. Psycho-Oncology 2003;12:8-23.

38. EORTC Quality Of Life Study Group. Manual EORTC QLQ-C30. Brussels, 1998.

39. Aaronson NK. The European organization for research of treatment of cancer QLQ-C30. Quality of life instrument use in international clinical trials in oncology. J Natl Cancer Inst 1993;85:365-376.

40. Sprangers MA, Groenvold M, Arraras JI et al. The European organization for research and treatment of cancer breast cancer-specific quality-of-life questionnaire module: first results from a three-country field study. J Clin Oncol 1996;14(10):2756-2768 
41. Jöreskog K, Sörbom D. Prelis 2. User's Reference Guide. Scientific Software International Inc.: Chicago, 1996.

42. Jacobsen PB, Meade CD, Stein KD, Chirikos TN, Small BJ, Ruckdeschel JC. Efficacy and costs of two forms of stress management training for cancer patients undergoing chemotherapy. J Clin Oncol 2002;20(12): 2851-2862.

43. Helgeson VS, Cohen S, Schulz R, Yasko J. Long-term effects of educational and peer discussion group interventions on adjustment to breast cancer. Health Psychol 2001;20(5):387-392.

44. Moorey S, Greer S, Bliss J, Law M. A comparison of adjuvant psychological therapy and supportive counselling in patients with cancer. Psycho-Oncology 1998;7: 218-228.

45. Bré dart A, Cayrou S, Dolbeault S. Letter to the Editor: Re: systematic review of psychological therapies for cancer patients: overview and recommendantions for future research. J Nat Cancer Inst 2002; 4(94): 1810 .

46. Adair G. The Hawthorne effect: a reconsideration of the methodological artifact. J Appl Psychol 1984;69(2): 334-345.

47. Stanton AL. Psychosocial concerns and interventions for cancer survivors. J Clin Oncol 2006;24(32):5132-5137.
48. Owen JE, Klapow JC, Hicken B, Tucker DC. Psychosocial interventions for cancer: review and analysis using a three-tiered outcomes model. Psycho-Oncology 2001; $10: 218-230$

49. Vos PJ, Garssen B, Visser AP, Duivenvoorden HJ, de Haes HC. Psychosocial intervention for women with primary, non-metastatic breast cancer: a comparison between participants and non-participants. Psychother Psychosom 2004.

50. Boesen EH, Ross L, Frederiksen K et al. Psychoeducational intervention for patients with cutaneous malignant melanoma: a replication study. J Clin Oncol 2005; 23(6): 1270 .

51. Classen CC, Kraemer HC, Blasey C et al. Supportive-expressive group therapy for primary breast cancer patients: a randomized prospective multicenter trial. Psycho-Oncology 2008;17(5): 438-477.

52. Cordova MJ, Giese-Davis J, Golant $M$ et al. Mood disturbance in community cancer support groups. The role of emotional suppression and fighting spirit. J Psychosom Res. 2003;55(5):461-467.

53. Scheier MF, Helgeson VS, Schulz R et al. Moderators of interventions designed to enhance physical and psychological functioning among younger women with early-stage breast cancer. J Clin Oncol. 2007;25(36): $5710-5714$. 